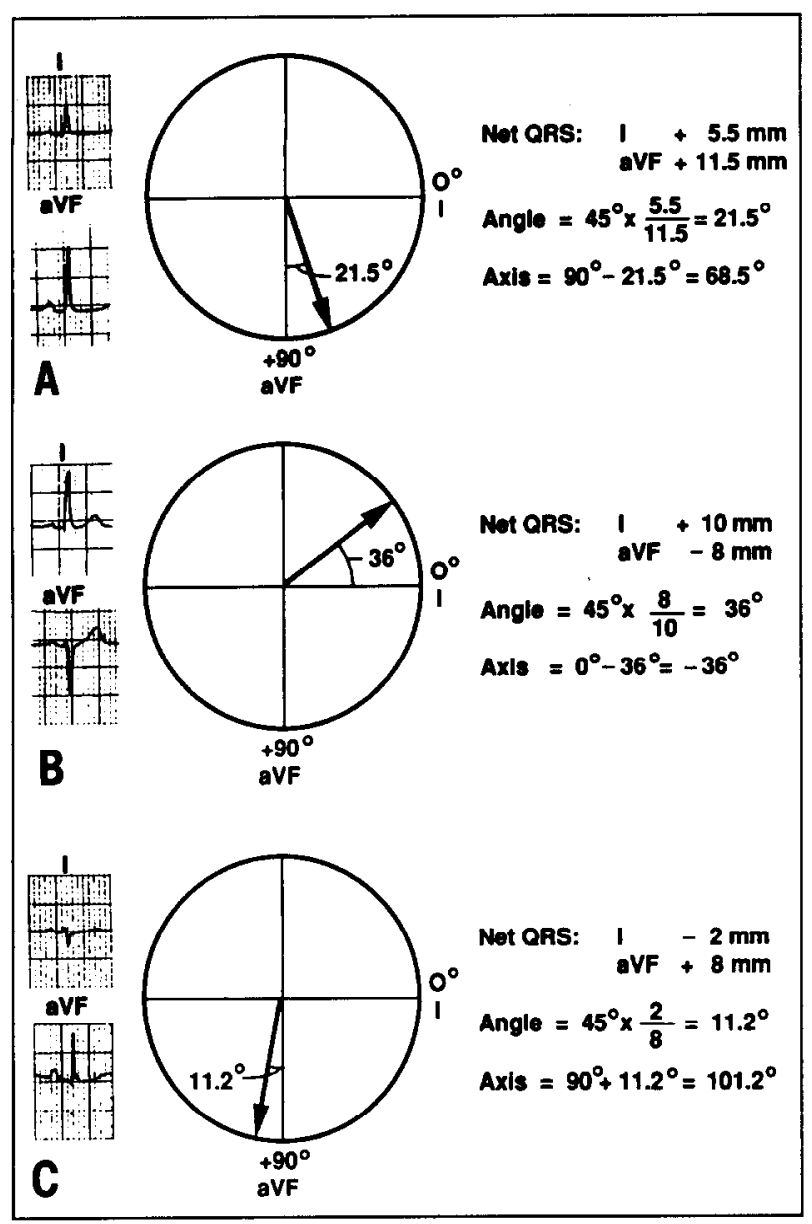

FICURE 1. Calculation of QRS axis using loads I and aVF in patients with normal axis (A), left axis doviation (B) and rightward axis (C) (see text).
$Q R S$ deflection in aVF is negative. Similarly, in Figure $1 C$, the angle of $11.2^{\circ}$ is added to $90^{\circ}$ (lead aVF, largest net $Q R S$ deflection) since the net $Q R S$ deflection in lead $I$ is negative.

Rapid calculation of the electrocardiographic frontal axis is desirable. The method described is simple and provides an acceptable approximation of the axis determined using the trigonometric tangent. The calculated angle may underestimate the true angle by less than $4.1^{\circ}$ without overestimation. Alternative methods to determine the axis are reliable but may require the use of tables or reference diagrams. ${ }^{3-6}$ Thus, advantages of this formula include its simplicity, which allows for rapid calculation of frontal plane axis without use of the more cumbersome hexaxial reference diagram or tables. It may be particularly useful where there is no equiphasic lead, such that Grant's method ${ }^{1}$ is not easily applicable. The mean frontal plane axis may vary by $35^{\circ}$ in an individual patient when different lead combinations are used. ${ }^{7}$ When more accurate determination is desired, an average of several lead combinations may be useful.?

1. Grant RP. Clinical Electrocardiography: The Spatial Vector Approach. Second edition. New York: McGraw Hill, 1970:8-43.

2. Hakki AH, Anderson GJ, Iskandrian AS, Segal BL. A simple method to determine the electrocardiograpic frontal plane axis. $J$ Electrocardiol 1982:15:285-288.

3. Laiken S, Laiken N, O'Rourke RA, Karliner JS. A rapid method for frontal plane axis determination in scalar electrocardiograms. Am Heart J 1973;85:620 623.

4. Zao ZZ. A geometric study of the relationship between limb leads and cardiac vector in the frontal plane. Am Heart J 1960;59:249-262.

5. Zao ZZ. Circular lead reference system. Am J Cardiol 1963:11:130-131. 6. Zao ZZ. Horizontal plane electrocardiographic vector: a study in conjunction with frontal projections. Cardiologia 1964:45:333-346.

7. Okamoto N, Kaneko K, Simonson E, Schmitt OH. Reliability of individual frontal plane axis determination. Circulation 1971;44:213-219.

\title{
Effect of Sampling Site on Doppler-Derived Right Ventricular Systolic Time Intervals
}

Elizabeth M. Shaffer, MD, A. Rebecca Snider, MD, Gerald A. Serwer, MD, Jane Peters, and Patricia A. Reynolds

E valuation of the pulmonary artery pressure and pulmonary vascular resistance is essential in the care of most children with congenital heart disease. Recent investigations have focused on determining a noninvasive technique for detecting pulmonary hypertension. Several different right ventricular (RV) systolic time intervals measured from the Doppler echocardiogram have correlated well with pulmonary trunk pressure and pulmonary vascular resistance measured at cardiac catheterization. ${ }^{1-8}$ In these studies, investigators have used multiple positions for the Doppler sample volume ranging from the RV outflow tract ${ }^{1-5}$ to the pulmonary trunk..$^{5-7}$ Recently, Panidis et al, ${ }^{9}$ using Doppler, reported a significant difference in the acceleration time measured from the RV

From the Department of Pediatrics, C.S. Mott Children's Hospital, University of Michigan Medical Center, Ann Arbor, Michigan. Manuscript received May 1, 1989; revised manuscript received and accepted December 6, 1989. outflow tract compared to that measured from the pulmonary trunk. Matsuda et al ${ }^{5}$ found no such difference between the 2 sampling sites. We determined the effect of Doppler sample volume position on all of the commonly used RV systolic time intervals in a group of patients evaluated in a pediatric echocardiography laboratory.

The study participants consisted of 23 patients. Seven patients had normal examinations while the other 16 had a variety of cardiovascular abnormalities including aortic stenosis, thoracic coarctation, atrial septal defect, small ventricular septal defect, atrioventricular septal defect, cor triatriatum, mitral valve prolapse, Marfan's syndrome, Kawasaki's disease and Wolff-ParkinsonWhite syndrome. The group included 10 females and 13 males whose ages ranged from 5 days to 25 years (mean 9.4 years). Each participant underwent a range-gated pulsed Doppler examination of the RV outflow tract from the parasternal short-axis view. The Doppler recordings were obtained using an Advanced Technology 


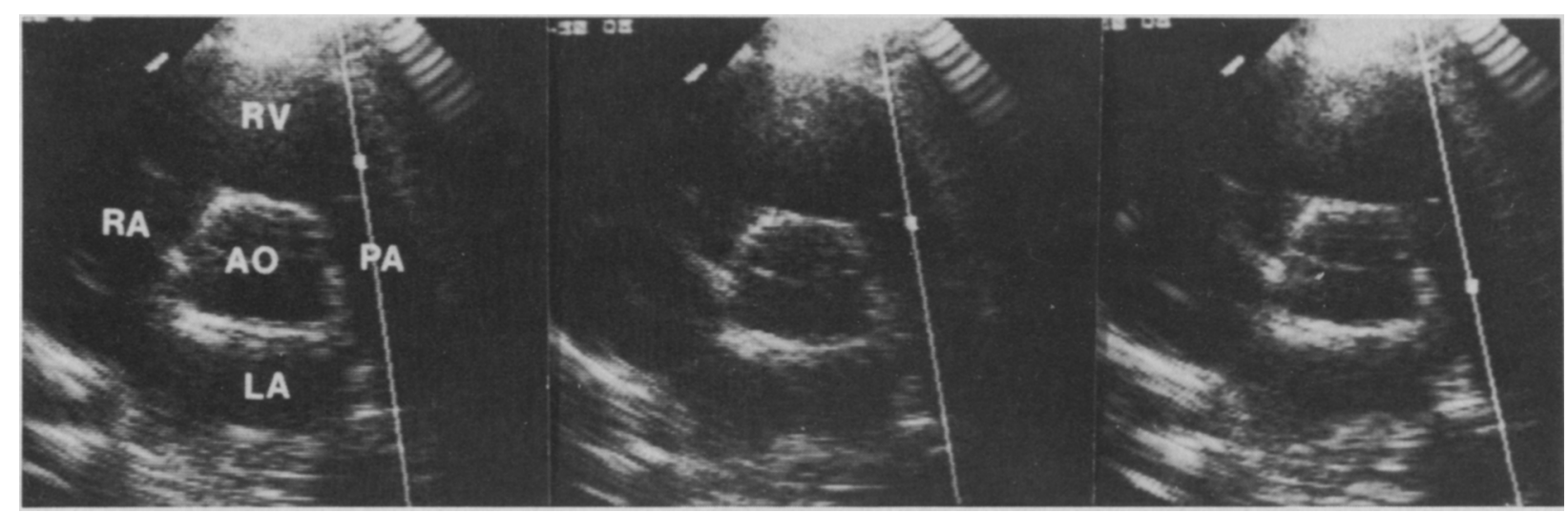

FIQURE 1. Parastemal short-axis views showing the 3 Doppler sample volume positionsi proximal to the pulmonary valve (left), just fistal to the pulmonary valve (middle) and midway between the pulmonary valve and pulmonary bifurcation (right). AO = aorta; $L A=$ left atrium; $P A=$ pulmonary artery; $R A=$ right atrium; $R V=$ right ventricle.

Laboratories UltraMark 8 imaging system and 5-, 3.5and 2.25- $\mathrm{MHz}$ mechanical transducers. Doppler tracings were recorded with the sample volume positioned in the right ventricle just proximal to the pulmonary valve, in the pulmonary trunk just distal to the pulmonary valve and in the pulmonary trunk midway between the pulmonary valve and the pulmonary trunk bifurcation (Figure 1). The Doppler tracings were recorded at a paper speed of $100 \mathrm{~mm} / \mathrm{s}$ and wall filter settings of 200 $\mathrm{Hz} . \mathrm{RV}$ systolic time intervals were measured (in $\mathrm{ms}$ ) from each sample volume position on all study participants using the Doppler spectral tracings and the simultaneous electrocardiogram. The preejection period was measured from the $Q$ wave of the electrocardiogram to the onset of flow on the Doppler tracing. The acceleration time was measured from the onset of flow to the peak velocity of flow. The ejection time was measured from the onset of flow to the end of flow (Figure 2). A minimum of 3 cardiac cycles was measured at each sample volume position. The following variables were derived from the measured time intervals: the preejection period corrected for heart rate was calculated as the uncorrected preejection period plus 0.39 times the heart rate, and the ejection time corrected for heart rate was calculated as the uncorrected ejection time plus 1.5 times the heart rate. In addition, the ratios of preejection period/acceleration time, acceleration time/ejection time and preejection period/ejection time were calculated. The variables measured at each site were compared using a period $t$ test and Bonferroni's correction for multiple comparisons. A 2-tailed p value $<0.04$ indicated a significant difference between sites.

Table I lists the results of comparisons of the $R V$ systolic time intervals obtained from the different sample volume positions. No differences were found in heart rate, preejection period, ejection time or these time intervals corrected for heart rate at the 3 sample sites. The acceleration time was significantly shorter distal to the pulmonary valve and midway to the pulmonary trunk when compared to that obtained proximal to the pulmonary valve. There was no difference in the acceleration time measured just distal to the pulmonary valve and the acceleration time measured midway to the pulmonary trunk. Because of the differences observed in the accel- eration time between sites, the acceleration time/ejection time ratio was significantly lower at both sites distal to the pulmonary valve compared to the site proximal to the pulmonary valve. The acceleration time/ejection time ratio just distal to the pulmonary valve was not different from the acceleration time/ejection time ratio measured midway in the pulmonary trunk. The preejection period/acceleration time ratio measured just distal to the pulmonary valve was significantly higher than the preejection period/acceleration time ratio measured proximal to the pulmonary valve. The preejection period/acceleration time ratio measured midway in the main pulmonary artery was also higher than that measured proximal to the pulmonary valve but this value did not reach statistical significance. The preejection period/ ejection time ratio was not different among the 3 sampling sites.

Several Doppler echocardiographic techniques have been used to estimate the pulmonary artery pressure non-

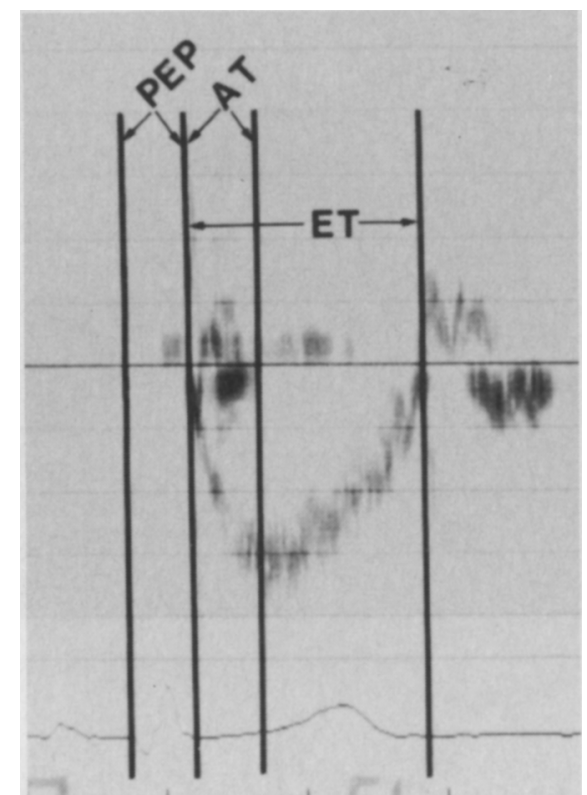

FIGURE 2. Pumonary artery Doppler tracing showing the measured systolic time intervals. AT = acceleration time; ET $=$ ejection time; PEP = preejection period. 
TABLE I Comparison of Doppler-Derived Right Ventricular Systolic Time Intervals and Ratios Measured at Three Sampling Sites in 23 Patients

\begin{tabular}{|lccc|}
\hline & Proximal Valve & Distal Valve & Midway MPA \\
\hline HR (beats/min) & 90 & 92 & 94 \\
PEP (ms) & $89 \pm 6$ & $88 \pm 5$ & $90 \pm 5$ \\
PEPc (ms) & $124 \pm 4$ & $125 \pm 4$ & $127 \pm 4$ \\
ET (ms) & $283 \pm 10$ & $287 \pm 11$ & $282 \pm 11$ \\
ETc(ms) & $410 \pm 11$ & $427 \pm 5$ & $423 \pm 6$ \\
AT (ms) & $119 \pm 8$ & $106 \pm 8^{*}$ & $106 \pm 7^{\dagger}$ \\
AT/ET & $0.42 \pm 0.02$ & $0.36 \pm 0.02^{*}$ & $0.37 \pm 0.02^{\dagger}$ \\
PEP/AT & $0.82 \pm 0.06$ & $0.94 \pm 0.07^{*}$ & $0.93 \pm 0.06$ \\
PEP/ET & $0.32 \pm 0.02$ & $0.31 \pm 0.02$ & $0.33 \pm 0.02$ \\
\hline
\end{tabular}

Values are mean \pm standard error of the mean.

* $p<0.04$ for proximal valve vs distal valve; ${ }^{\dagger} p<0.04$ for proximal valve vs midway

$\mathrm{AT}=$ acceleration time $\mathrm{ET}=$ ejection time; $\mathrm{ETC}=$ heart rate-corrected ejection time; $\mathrm{HR}=$ heart rate; $\mathrm{MPA}=$ main pulmonary artery; $\mathrm{PEP}=$ preejection period $\mathrm{PEP}$ $=$ heart rate-corrected preejection period.

invasively. Chan et $\mathrm{al}^{2}$ showed that the measurement of the peak velocity of the tricuspid regurgitant jet was the most useful and practical technique, but they could obtain the jet in only $72 \%$ of the patients studied. Therefore, Doppler techniques other than measurement of the tricuspid regurgitant jet must be used to estimate pulmonary artery pressure in some patients.

Several different RV systolic time intervals have proved useful for estimating pulmonary artery pressure noninvasively. ${ }^{1-8}$ Of these intervals, the acceleration time and ratios involving the acceleration time have correlated best with catheterization measurements of pulmonary pressure and vascular resistance. ${ }^{1,6,7}$ Systolic time intervals are influenced by factors such as heart rate, contractility, ventricular loading conditions and drug therapy. Therefore, they are limited in their ability to evaluate pulmonary hypertension. In this study, we found that technical factors such as the position of the Doppler sample volume can also influence the noninvasive measurement of RV systolic time intervals.

Different investigators have used different Doppler sampling sites to evaluate patients with pulmonary hypertension. It is as yet unknown which site provides the best correlation with catheterization measurements of pulmonary artery pressure and resistance. In the meantime, if Doppler measurements of acceleration time or ratios involving acceleration time are used to predict pulmonary artery pressure, care must be taken to standardize sample volume position.

1. Kitabatake $A$, Inoue $M$, Asao $M$, Masuyama $T$, Tanouchi $J$, Morita $T$, Mishima M, Uematsu M, Shimazu T, Hori M, Abe H. Noninvasive evaluation of pulmonary hypertension by a pulsed Doppler technique. Circulation 1983; 68:302-309

2. Chan K, Currie PJ, Seward JB, Hagler DJ, Mair DD, Tajik AJ. Comparison of three Doppler ultrasound methods in the prediction of pulmonary artery pressure. JACC 1987,9:549-554.

3. Martin-Duran R, Larman M, Trugeda A, Vazquez de Parda JA, Ruano J, Torres A, Figueroa A, Pajaron A, Nistal F. Comparison of Doppler-determined elevated pulmonary arterial pressure with pressure measured at cardiac catheterization. Am J Cardiol 1986;57:859-863.

4. Isobe M, Yazaki Y, Takaku F, Koizumi K, Hara K, Tsuneyoshi H, Yamaguchi T, Machii K. Prediction of pulmonary arterial pressure in adults by pulsed Doppler echocardiography. Am J Cardiol 1986:57:316-321.

5. Matsuda M, Sekiguchi T, Sugishita Y, Kuwako K, Iida K, Ito I. Reliability of non-invasive estimates of pulmonary hypertension by pulsed Doppler echocardiography. Br Heart $J$ 1986:56:158-164.

6. Dabestani A, Mahan G, Gardin JM, Takenaka K, Burn C, Allfie A, Henry WL. Evaluation of pulmonary artery pressure and resistance by pulsed Doppler echocardiography. Am J Cardiol 1987;59:662-668.

7. Kosturakis D, Goldberg SJ, Allen HD, Loeber C. Doppler echocardiographic prediction of pulmonary arterial hypertension in congenital heart disease. $A m J$ Cardiol 1984;53:1110-1115.

8. Ritter SD, Cooper RS, Golinko RJ. Noninvasive assessment of pulmonary hypertension, pulmonary vascular reactivity, and intracardiac shunting: pulsed Doppler application. J Cardiovasc Ultrasonography 1984;3:325-328.

9. Panidis IP, Ross J, Mintz GS. Effect of sampling site on assessment of pulmonary artery blood flow by Doppler echocardiography. Am J Cardiol 1986;58: $1145-1147$. 